\title{
Approaching SARS-COV-2 through Immune boosting herbs - A scoping review
}

\author{
Review Article
}

\section{Kirubhakaran S M1* , Vadivelan S2, Sarojini T33, Mathukumar $\mathbf{S}^{4}$}

1. Reader, Department of Sattam Sarntha Maruthuvamum Nanju Maruthuvamum,

2. Lecturer, Department of Maruthuvam, 3. Lecturer, Department of Udalthathuvam, 4. Principal, Sri Sairam Siddha Medical College and Research Centre. Chennai. Tamilnadu.

\begin{abstract}
SARS- COV-2 a RNA virus which produce a serious ill-effects and brings the world under a common word Lockdown. Thus lockdown brings down the rate of spreading of cases, but severity of the illness is managed by combined therapy both Modern and Traditional system of medicine (Siddha, Ayurveda, Homeopathy). Immune boosting herbs is need of the hour in this pandemic situation. Immune boosters improves overall immunity of the host through cellular and humoral immunity. During Dengue pandemic situation a polyhebral preparation Nilavembu kudineer- siddha sastric medicine and Carica papaya leaf extract highly works. During this pandemic covid situation Tulsi, Lemon, Arathai and siddha sastric medicine kabasura kudineer works in prevention, mild and moderate cases. There is a growing interest to the herbal medicine to modulate the complex immune system in preventing infections. The aim of the review is to give hope and to boost the research in herbal medicines during this pandemic situation.
\end{abstract}

Key Words: SARS-COV-2, Immune boosting herbs, Nilavembu kudineer, Kabasura kudineer, Immunomodulator, Siddha.

\section{Introduction}

In developing countries more than $70 \%$ of the populations have trust in Traditional Medicines, mostly plant drugs used for their primary health demands. Most of the plants possess biologically active constituents- Alkaloids, Flavonoids, Tannins, and phenolic compounds. In Recent years many dreadful viral fever have been reported in India and other Asian countries like Dengue, chikungunya, swine flu etc. In 2019 December, Wuhan (China) reported a series of cases greatly resembling viral pneumonia (1). WHO declared COVID-19 a pandemic disease on March 11, 2020 (2). The common symptoms are High grade fever, cough, sneezing, fatigue, diarrhoea, headache and dyspnoea (3). The mode of transmission is through close contact with affected persons via respiratory secretions from mouth, eye, and nose (4).

However SARS COV- 2 symptoms resembles common cold infections but severe acute respiratory syndrome, multi organ failure and even death in more severe cases (5). Researchers finding their best way to cure or prevent COVID-19 infection including herbal medicines. As Herbal medicines possess immunomodulatory effects and its potential in preventive and therapeutic agents for COVID-19

* Corresponding Author:

Kirubhakaran S M

Reader, Department of Sattam Sarntha

Maruthuvamum Nanju Maruthuvamum, Sri Sairam

Siddha Medical College and Research Centre.

Chennai. Tamilnadu India

Email Id: kirubhakaran@sairamsiddha.edu.in infection (6). Ministry of AYUSH formed a Guidelines for siddha practitioners for COVID-19 released recently its official publication in May 31, 2020. Kabasura kudineer chooranam, Nilavembu kudineer chooranam, Notchi kudineer chooranam, Vishasura kudineer chooranam, Amukkara chooranam, Thalisadhi chooranam, Adhimathura chooranam, Thippli Rasayanam, Nellikkai legiyam are siddha sastric formulations mentioned in the guidelines for siddha practitioners for COVID-19. These formulations shows a possible effects against covid-19 in siddha covid care centre.

Seenthil, Inji, Nilavembu, Manjal, Amukkara, Nellikkai, Arathai, Tulsi, Milagu, Kadukkai are taken in account for review by the author as most of these herbals are one of the ingredients of above mentioned sastric siddha formulations. These herbs are widely used in siddha system from ancient times for their actions- Veppagatri (Febrifuge), Muraiveppagattri (Anti-Periodic), Udal thaetri (Alterative), Kozhaiagattri (Expectorant). The above mentioned siddha preparations are common advisory for siddha in treating Covid-19. So the author made an attempt to show the immunomodulatory actions of these herbs in this article which may helpful for Researchers, scientists, practitioners during this pandemic situation for prevention and therapeutic value.

\section{Materials and Methods}

All the information regarding above said aim have compiled from previous research work in immunomodulatory activity of herbs published on various peer reviewed journals and available on PubMed, Google scholar etc. 


\section{Immunomodulator}

Immunomodulator is defined as a substance that influence the specific immune function directly or modifies the immunoregulatory network to achieve an indirect effect. Through the dynamic regulations of cytokines, the immunoregulators alters the activity of immune functions. Immunomodulation activity occurs mainly by stimulation of phagocytosis, activation of Macrophages, stimulation of lymphoid cells, increasing antigen specific immunoglobulins and circulating WBC count (7).

\section{Immunomodulatory herbs}

Traditional system of medicine has a widespread acceptability as therapeutic effects against Diabetes, Arthritis, Liver impairments, Memory enhancer, Respiratory disorders, gastrointestinal troubles and cancer. Researchers found that herbs possess Anti-inflammatory, Antitussive, anti-cancer, bronchodilator, immunomodulator, hepatoprotective, Anti-oxidant activities (8). Immunomodulatory herbs are widely used in Rasayanam -a compound herbal preparations in siddha system of medicine. They improves overall immune response of the host, by increasing cellular and humoral immunity by stimulating T-cell and B-cell, by increasing cytokine secretions. Nowadays Researchers showing keen interest in developing immunomodulatory herbal products. The potential effect of immunomodulators in SARS COV-2 will reduce the risk factors and serious ill-effects of COVID-19.

\section{Tinospora cordifolia (Thumb.)Miers.}

Sharma demonstrated the study of Tinospora cordifolia has the Immunomodulatory activities by isolating active compounds namely $\mathrm{N}$ formylannonain,11-hydroxymustakone , N-methyl-2pyrrolidone,cordifolioside A, mag-no Florine, tinocordiside, syringin by nuclear magnetic resonance (NMR) and mass spectrometry (MS) Method, in which cordifolioside A, syringin have been reported to possess Immunomodulatory effect. The remaining has the capacity to enhance the phagocytic effects .The result shows that 7 active compounds of Tinospora cordifolia has the Immunomodulatory action (9).

Vaibow demonstrated with Healthy Sheep Blood injected to Male Wister rat, sterilized Alsever solution (1:1) mixed with Sterilized phosphate Buffer saline \& Sheep RBC was made as a pellets. After the administration of Alcoholic extract ( $100 \mathrm{mg} / \mathrm{kg} /$ p.o. ) , the Antigenic cellular responses dealt with DTH( Delayed Type Hypersensitivity ) detected by Foot pad swelling method, measuring the time interval of $8,24,48 \& 72 \mathrm{hrs}$ noticed the increase in swelling. This demonstration proves that Tinospora cordifolia alcoholic extract has the Immunomodulatory Action (10).

\section{Zingiber officinale Roscoe.}

Ginger widely used as a spice and medicine in India and China from ancient days. Administration of chemotherapy in cancer patients potentially increase the oxidative stress. This is noted by elevation of Lipid peroxidation and Nitric oxide and reduction in antioxidants. The Immunomodulating activity of Ginger is evaluated through Antioxidant Enzymes level (CAT, SOD, and GSH). The most active compound in Ginger is 6-Gingerol (pungent compound) claimed to have Antioxidant activity. Author kwanjit et al 2017 done a Pilot, randomized, double-blind, placebo-controlled trail to show the Antioxidant activity of Ginger. Author assigned two groups in which one will be Placebo and another one will receive ginger extract (6-Gingerol) (11).

\section{Andrographis paniculata (Burm.f.) Nees.}

Andrographolide, isolated compound from Andrographis paniculata Exhibits immunomodulatory property by macrophages activation, and regulate Antibody production and Antigen specific IL-4 producing splenocytes. In vivo study of mice it has proved or showed that andrographolide possess the capacity of regulating the adaptive immune response. Conducting the experiment with mice, the $\mathrm{HBsAg}$ $(1 \mu \mathrm{g} /$ mouse ) \& Andrographolide has been administered in Intramuscular \& Intraperitoneal regions respectively for about 7 consecutive days. From the day of primer at which the primary dose administered was kept in the count then with the interval of 4 weeks, the boosting dose has been injected to the mice. Later, after 2 weeks another dose was injected.The total periods of vaccine administration for the mice was counted to be 6 weeks. After the vaccination process have set done, they are observed that the immune response has been implemented. This consequences was caused after injecting for administering the boosting dose. They also Noted that HBsAg titre has been reduced after observing via the study of histological examination of the Isolated cells of spleen (splenocytes -23/10`6 spleen cells $) \& \operatorname{HBs} \operatorname{Ag}(0.5 \mu \mathrm{g} / \mathrm{ml})$ was decreased by $40 \%$ in immunized Mice .In addition to this, it produces IL(Interleukin)- 4 cells. This has been proven by the ELISPOT Test (Invitro Method). From this Experimental study we could conclude that the Andrographolide has the Immunomodulatory Action (12).

The Win's Neutralization assay Test(Sheeja et al.,2007) demonstrated in BALB/c mice, the study deals with the administration of andrographolide in the ELA Thymoma cells \& observed that increased production of CTL ( cytotoxic T lymphocyte) due to the enhanced secretion of IL-2 \& IFN-7 by T- cells \& the growth of tumour gets reduced. The ELISA \& Gene expression (GEArray ${ }^{\mathrm{TM}} \&$ RT-PCR) Test (Xu et al., 2007) deals with the administration of andrographolide \& Andrographis paniculata extract, S.typhimurium vaccine to the immunized Mice \& Results in the increased production of IgG Antibody against S.typhimurium \& Cell mediated response against salmonellosis. Histological examination in splenocytes of immunized Mice, induces the production of Interferons which conclude that Andrographis paniculata has immunomodulatory action (13). 


\section{Curcuma longa $\mathrm{L}$.}

Curcumin active compound of curcuma longa, increase the macrophage phagocytic activity. S.Antony, R.Kuttan \& G.Kuttan jointly demonstrated that Curcumin has the Immunomodulatory effect by extracting the active ingredient curcumin from Curcuma longa \& Analysis initiated by administering curcumin in the BALB /c mice \& it induced the production of WBC count (15-290) against the Sheep RBC.It also increases the Plaque Forming Cells (PFC)after the immunization of mice. The Bone marrow cellularity $(16.9 \times 106$ cells/ femur) \& Alpha esterase positive cells (1622/4000 cells) were enhanced by the administration of Curcumin .Hence it shows that Curcumin possess Immunomodulatory Action (14).

Curcumin has many medicinal values \& Immunomodulatory activities. They proved with the upcoming demonstration deals with Healthy Albino mice immunized with Sheep RBC. Polymeric Nano particles (Lactic-co-glycolic acid) used for encapsulation. Oral administration of Nano curcumin 10 $\mathrm{mg} / \mathrm{kg}$ for 10 days. Cell mediated \& Humoral Immunity responses helps to assess the Immunomodulatory Activity, Determined by 2 Tests namely Hemagglutination \& DTH (Delayed Type Hypersensitivity). While injecting 5-10 mg $/ \mathrm{kg}$ observed that the Nanoparticles increases Antibody production by $9 \pm 1$ times $\&$ detected by the enhanced WBC production, weight of Lymphoid organs when compared with that of normal particles of Curcumin .Hence proved that Nanoparticles of Curcumin has the Immunomodulatory action(15).

\section{Withania somnifera (L) Dunal.}

Ghosal et al 1988 reported the roots of several varieties of Withania somnifera contains two glycowithanolides (sitoindoside IX and sitoindoside X). These two new compounds possess immunomodulatory activity by elicitation of peritoneal macrophages of mice. Significant increase in macrophages noted in Group II and III treated with Sitoindoside XI \& X respectively. The cells were counted at intervals of 48 hrs and 72 hrs. Enzyme activity is also noted through Tumour associated macrophages and Acid phosphatase activity. These effects suggest the immunostimulatory effect of two compounds (16).

Demonstration with 18 Swiss Albino Adult male mice (25-35 g) of 4 weeks of age, divided into 3 groups \& Diets were implemented with Withania somnifera extract ,milk, synthetic foods \& their Blood samples were collected in which they observed that IgG present in the serum confirmed by ELISA Test.Hence it shows that Withania somnifera extract has Immunomodulatory effect. Next Method deals with the collection of peritoneal fluid from Male Albino mice in which count of macrophages were noted. The Abdominal skin was swabbed with Alcohol (70\%), then skin was removed \& DMEM (Dulbecco Modified Eagle Medium ) with Ham's F-12 medium (8ml) was injected into the peritoneal cavity using $26 \mathrm{G}$ needle with gentle massage over the Abdominal region \& collecting peritoneal exudate (Approximately $5 \mathrm{ml}$ ) using 22G needle. Phagocytosis was observed under oil immersion microscope at $1000 \times$ magnification. Noted that lymphocytes were proliferated in the spleen of mice, determined by MTT (3-[4, 5-Dimethyl thiazol -2yl]-2, 5-Diphenyltetrazolium bromide) assay Test described by Mosmann (17).

Suresh et al Proves that Ashwangandha churna has Immunomodulatory effect in which Withania somnifera also present in it. Sheep RBC shows cellular immune response formed, then detected by 2 Tests namely, Foot pad swelling \& Neutrophil Adhesion Test.Its identified via Oral administration, reports the increase in Neutrophil Adhesion \& DTH (Delayed Type Hypersensitivity) Response. Albino wistar rats (180-200 g) used for the recent studies. Their cells got isolated \& Fresh Sheep RBC in Alsever solution washed for 3 times in $0.9 \%$ saline \& concentration of $0.5 \times 109$ cells / $\mathrm{ml}$ for immunization of Albino wistar rats takes place. Ashwagandha churna was orally administered for about 14 days with an initial dose of $50 \mathrm{mg} / \mathrm{kg} /$ day. Observed that increase in swelling of foot \& increased production of DTH \& Neutrophil Adhesion. This assessed that the Ashwangandha churna has the Immunomodulatory Action (18).

\section{Emblica officinalis Gaertn.}

Aqueous extract of deseeded, dried and powdered fruit of Emblica officinalis obtained for Immunomodulatory activity estimation. Male Swiss albino mice is used, all the mice were sensitized with SRBC antigen containing $1 \times 10^{8}$ cells intraperitoneally. Group II \& III receive aqueous extract of Emblica officinalis at dose level of $100 \mathrm{mg}$ and $200 \mathrm{mg} / \mathrm{kg}$ body weight/ day respectively. Haemagglutination antibody titre and Delayed type of Hypersensitivity is estimated on day $12^{\text {th }}$ and day $19^{\text {th }}$ respectively. Increased HA antibody titre and DTH activity is noted in Emblica extract treated mice. This may be due to the cell mediated and Humoral mediated Response (19). Nellikai improve the immunity by augmenting both humoral and cell mediated immune by increasing IL-2 \& Gamma IFN productions (20).

\section{Alpinia galangal (L.)Wild.}

Bendjeddou D et al 2003 compared the immunomodulatory effects of Anacyclus pyrethrum, Alpinia galangal and Citrullus colocynthis, in which Alpinia galangal shows positive way in immunomodulating action. The Method involves the Collection of spleen from mice \& kept in Hank's balanced salt solution (HBSS).In order to obtain the homogeneous cellular suspension they were made into pieces \& Lysis of erythrocytes takes place with Ammonium chloride $(0.8 \%, \mathrm{~W} / \mathrm{V})$. Centrifugation process have set as side \& pellets Cells washed 3 times using phosphate buffer saline .After counting the Number of cells, using Haemocytometer shows that $95 \%$ of splenocyte proliferation was assay. Experiment with 6 weeks mice, divided in 7 groups, each has 6 mice, they were immunized with Sheep RBC with $0.5 \mathrm{ml}$ of Phosphate buffer saline. The mice was immunized with administration of various extracts at 
dosage levels of 100-200 $\mathrm{mg} / \mathrm{kg}$ for 5 days. Here it comes the foot pad method were injection of $50 \mu \mathrm{O}$ Of SRBC in the right front foot while in the left with same quantity of physiology solution. Assessing the changes occurred in this assay was noted to be have increased foot weight.(21).Jain et al 2012, in his studies observed that flavonoid fractions of Alpinia galangal express immunomodulatory activity through $\mathrm{T}$ cell proliferation/ splenocyte proliferation (22).

\section{Ocimum scantum Linn.}

The hot aqueous extract of Ocimum scantum leaves subjected to estimate the immunomodulatory activity in chicken. Jayati et al 2013 used poultry as an experimental model in order to show the antibacterial immune modulation effects of Ocimum scantum. The author used twelve chicks for the experiment dividing into two groups. Both groups are immunized with salmonella typhimurium ' $\mathrm{O}$ ' antigen, along with this one group is treated with Placebo and for another group hot aqueous extract was administered orally at the dose of $250 \mathrm{mg} / \mathrm{kg}$ body weight. Humoral immune response (antibody titre) and Cell mediated immune response is noted by indirect ELISA and DNCB test respectively. There was a vast difference in antibody titre between hot aqueous extract of Ocimum scantum and Placebo group. CMIR is estimated by skin hypersensitive reaction. Notable increase in skin thickness is seen Ocimum scantum fed chicken group. Thus Tulsi exerts both HIR and CMIR (23).OS seed oil appears to modulate both humoral and cell mediated immune responsiveness and GABAergic pathways (24).

\section{Piper longum $\mathrm{L}$.}

Chauhan khusbu proved that Piper longum has Immunomodulatory effect in demonstrations with mice, which involves 3 tests namely, HA (Haemagglutination Titre), Phagocytic index \& MMI (Macrophage Migration Index). The Immunomodulatory Action was more effective Even in mild dose $(225 \mathrm{mg} / \mathrm{kg}) \&$ in heavy doses it observed to be lowered. The study after injecting the pippali rasayana (Piper lingum added compound medicine) with Giardia lamblia to the mice, has produced more macrophages as reported with increased MMI \& phagocytic Effects .Hence this proves that the Piper longum has prominent Immunomodulatory Activity (25).

\section{Terminalia chebula Retz.}

Immunomodulator activity is expressed by assessing the Mitochondrial Antioxidant Enzymes level. Antioxidant Enzymes Catalase (CAT), Superoxide dismutase (SOD), Reduced Glutathione (GSH) plays an important role in Immunomodulating Activity. Vaibhav et al 2011 expressed the Immunomodulator activity of the alcohol extract of Terminalia chebula Retz dried ripe fruits at the cellular level. The author observed Terminalia chebula alcoholic extract treated group shows increase in level of Antioxidant enzymes CAT, SOD, GSH and decrease in LPO (lipid peroxidation).Lymphocyte proliferation assay also determined using ELISA reader. The expression of
Cytokines levels IL-2, IL-10 and TNF- $\alpha$ done by RTPCR analysis. The results indicates the level of cytokines increased in Terminalia chebula treated group when compared to vehicle and cyclophosphamide treated group (26).

DLC (Differential leucocyte count), Phagocytic activity and Zinc sulphate Turbidity test was administered to identify the immunomodulatory activity of Terminalia chebula Retz. The percentage of Neutrophil in the Terminalia chebula alcoholic group identified to be almost equal, whereas the percentage of Lymphocytes decreases significantly in SRBC treated group when compared to Terminalia chebula alcoholic extract treated group. The level of monocyte shows increased when compared to SRBC sensitized and cyclophosphamide treated group. Phagocytic index is determined through $30,60,90,120$ minutes intervals. After 120 minutes Maximum Phagocytic index is identified in Terminalia chebula alcoholic treated group when compared to SRBC sensitized and cyclophosphamide treated group. The level of Serum Immunoglobulin increases significantly which is observed in ZSTT. Zins sulphate turbidity test used to determine Humoral immunity (27).

\section{Discussion and Conclusion}

Wide variety of research is necessary in this pandemic situation to reduce the ill-effects and to prevent the death rate in COVID-19. Immunomodulators plays an important role in both specific and nonspecific immunity. Traditional system of medicine possess wide range of immunomodulating herbs in their preparations. Present review gives an overview of widely investigated plant derived compounds, which exhibit potent effect on $\mathrm{C}$ and $\mathrm{H}$ immune function and these herbs are the key ingredients in Sastric siddha preparation mentioned in Guidelines for siddha practitioners for covid-19. Plant derived compounds shows promising immunomodulatory effects which is a need of hour in this pandemic. This article is aimed to express the most potent herbs that stimulating both cellular and humoral immunity evaluated by the researchers. Zingber officinalis, Tinospora cordifolia, Andrographis paniculata, Terminalia chebula are the key ingredients in Kabasura kudineer a poly herbal preparation in siddha system of medicine, has an evident in posseing immunomodulating activity. Young scientist and researchers should involve herbal drugs in future studies to newer drug evaluation in this pandemic.

\section{Reference}

1. https://science.thewire.in/health/china-had-firstcoronavirus-case-in-november-2019-itself/ $13 / 03 / 2020 /$

2. https://www.euro.who.int/en/health-topics/healthemergencies/coronavirus-covid-19/news/news/ 2020/3/who-announces-covid-19-outbreak-apandemic $12 / 03 / 2020$

3. Chaplin Huang, Heming Wang, Xing Wang, Lili Ren et al ,Clinical features of patients infected with 
2019 novel coronavirus in Wuhan, china. The Lancet, 2020; 395(10223):497-506.

4. Sasmita Poudel Adhikari, Sha Meng, Yu-ju Wu, YuPing Mao et al. Epidemiology, causes, clinical manifestations and diagnosis, prevention and control of coronavirus disease (COVID-19) during the early outbreak period-a scoping review. Infectious Diseases of poverty, 2020; 9(29): 1-22.

5. Vincent JL, Taccone FS. Understanding pathways to death in patients with covid 19. Lancet Respir Med.2020; 8(5):430-432.

6. Rhea Veda bigraha, Hastono Ridwansyah et al. Traditional Herbal Medicine candidates as complementary Treatment for COVID-19: A Review of their Mechanism, pros and cons, Hindawi. Evidence based complementary and Alternative medicine, 2020; 1-12.

7. Dinesh Kumar, Vikrant Arya et al. A review of immunomodulators in the Indian traditional health care system .Journal of Microbiology immunology and infection 2012; 45:165-184.

8. Patel PM, Patel NM Goyal RK. Quality control of herbal products. The Indian pharmacist 2006; 5:26-30.

9. Sharma v, Bala M, Kumar N, Singh B, Munshl RK, Bhalerao S. Immunomodulatory active compounds from Tinospora cordifolia. J Ethnopharmacol, 2012; 141(3):918-926.

10. Vaibhav D. Aher, Arunkumar Wahi. Pharmacological study of Tinospora cordifolia as an immunomodulator. International journal of current pharmaceutical research, 2010; 2(4):52-54.

11. Kwanjit Danwilai, Jitprapa Konmun, Bung-orn Sripanidkulchai, Suphat Subongkot. Cancer Manag Res.2017; 9:11-18.

12. Wei Wang, Jing Wang et al. Immunomodulatory activity of andrographolide on Macrophage activation and specific antibody response. Acta Pharmacologica Sonica, 2010; 31(2):191-201.

13. Rafael. A Burgos, Maria. A hidalgo et al. Immunomodulatory activities induced by Andrographis paniculata. Standardization of Herbal/Ayurvedic Formulations.24; 425-441.

14. Antony $S$, kuttan R, and kuttan G. Immunomodulatory activity of curcumin. A journal of Molecular and cellular immunology, 1999; 28(5-6):291-303.

15. Funmilayo I.D A.folayan, Blessing Erinwusi, and Oyetunde T.Oyeyemi. Immunomodulatory activity of curcumin- entrapped poly D, L-lactic-co-glycolic acid nanoparticles in mice. Integrative Medicine Research 2018; 7(2):168-175.
16. Shibnath Ghosal, Jawahar Lal, Radheyshyam Srivastava et al. Immunomodulatory and CNS effects of Sitoindosides IX and $\mathrm{X}$, Two New Glycowithanolides from Withania somnifera. Phytotherapy Res 1989; 3(5):201-206.

17. Moharkar Kanhaiya, S P Digambar, Sumit Arora, Suman kapila, R.R.B.Singh. In vivo effect of herb (withania somninifera) on immunomodulatory and antioxidative potential of milk in mice. Food and Agricultural immunology, 2014; 25(3):443-452.

18. Suresh gupta M, Shira Prasad H N, Kharya M D, and RanaA C. Immunomodulatory activity of the Ayurvedic formulation Ashwagandha churna. Pharmaceutical Biology, 2006; 44(4):263-265.

19. Suja.R.S, Nair.A.M.C, Sujitha.S, Preethy.J, Deepa.A.K. Evaluation of Immunomodulatory Potential of Emblica Officinalis fruit pulp extract in Mice. Indian J. Anim. Res, 2009: 43(2); 103-106.

20. Ganju, L. D.karan, S.chanda, K K Srivastava, R C Sawhney W Selvamurthy. Immunomodulatory effects of agents of plant origin. Biomed Pharmacother, 2003; 57 (7):296-300.

21. Bendjeddou D, Lalaoui K, Satta D. Immunostimulating activity of the hot water soluble polysaccharide extracts of Anacyclus pyrethrum, Alpinia galangal and Citrullus colocynthis. J Ethnopharmacol.2003 Oct: 88(2-3): 155-60.

22. Alok pal, Jain, Rajesh Singh pavar, Santram Lodhi and Abhay K.Singhal. Immunomodulatory and antioxidant potential of Alpinia galangal Linn. Rhizome. Pharmacognosy communications, jul-sep 2012; 2(3); 30-37.

23. Jayati, Bhatia.A.K, Amit Kumar, Anjana goel, Anu Rahal. Immunomodulatory activity of hot aqueous extract of Ocimum scantum leaves. Indian J.Comp.Microbiol.Immunol.Infect.Dis.2013:34(1);3 3-37

24. Mukherjee R, Dash PK, Ram GC. Immunotherapeutic potential of Ocimum sanctum (L) in bovine subclinical mastitis. Res Vet Sci. 2005; 79(1):37-43.

25. Chauhan khushbu, Solanki Roshni et al. Phytochemical and therapeutic potential of Piper longum Linn a Review. IJRAP, 2011; 2(1):157-161.

26. V Aher, A wahi. Immunomodulatory activity of Alcohol extract of Terminalia chebula Retz Combretaceae. Tropical journal of pharmaceutical research. October 2011; 10(5):567.

27. Vaibhav D Aher et al. Immunomodulatory effect of alcoholic extract of Terminalia chebula ripe fruits. Journal of pharmaceutical sciences and Research. 2010; 2 (9); 539-544. 